\title{
REGENERAÇÃO HEPÁTICA INDUZIDA POR RESSECÇÃO SEGMENTAR DO FÍGADO, EM RATO
}

\section{HEPATIC REGENERATION INDUCED BY SEGMENTAL LIVER RESECTION, IN RATS}

\author{
Andy Petroianu, TCBC-MG ${ }^{1}$ \\ Carlos Roberto Messeder Esquerdo ${ }^{2}$ \\ Alfredo José Afonso Barbosa ${ }^{3}$ \\ Luiz Ronaldo Alberti ${ }^{4}$
}

\begin{abstract}
RESUMO: Objetivo: Avaliar a regeneração progressiva do parênquima hepatocitário, nos seus aspectos macro e microscópicos, em pós-operatório imediato e tardio de ressecção segmentar do fígado. Método: Foram estudados 10 ratos machos albinos da raça Wistar, pesando entre 250 e 300 gramas, submetidos à hepatectomia parcial de lobo esquerdo, com retirada de cerca de $20 \%$ da massa total do órgão. Os animais foram divididos aleatoriamente em dois grupos $(n=5)$ para estudo no $7^{\circ}$ (Grupo 1) e $21^{\circ}$ (Grupo 2) dias pósoperatórios. Decorrido o tempo de acompanhamento, avaliou-se o aspecto macroscópico e microscópico do fígado. Resultados: No Grupo 1, após sete dias, os animais apresentavam a cavidade abdominal com poucas aderências. O fígado mostrava reação cicatricial no local da ressecção, porém seu tamanho já era próximo ao normal. O exame histopatológico mostrou freqüentes sinais de poliploidia dos hepatócitos, além de tecido de granulação frouxo e desordenado, acompanhado de escasso infiltrado de células inflamatórias. O Grupo 2 , após 21 dias, mostrava poucas aderências na cavidade abdominal, e o fígado com aspecto e dimensões próximos ao normal. A histologia mostrou tecido cicatricial mais denso, ordenado, sem sinais inflamatórios. Observou-se apenas pequeno grau de poliploidia hepatocitária. Conclusão: Após remoção cirúrgica de 20\% do parênquima hepático houve aumento temporário da renovação celular verificado por poliploidia hepatocitária.
\end{abstract}

Descritores: Fígado; Regeneração hepática; Poliploidia.

\section{INTRODUÇÃO}

O fígado, sob condições normais, apresenta uma reduzida reprodução celular ${ }^{1,2}$. A proliferação hepatocitária pode ser estimulada por diferentes fatores, entre os quais se destacam a destruição do fígado por trauma ou infecção ${ }^{3}$. Cerca de $30 \%$ do parênquima hepático normal é compatível com a sobrevida e manutenção das funções hepáticas ${ }^{3} \mathrm{e}$ até $20 \%$ do remanescente hepático é capaz de rege- nerar um fígado no tamanho do espaço em que ele se encontra. Essa recuperação decorre do aumento do tamanho das células hepáticas (hipertrofia), aliado a uma rápida divisão e multiplicação celular (hiperplasia). Tais características permitem hepatectomias repetidas, desde que complicações, tais como infecções e anoxia, sejam evitadas.

Controvérsias existem a respeito da relevância das alterações de fluxo sangüíneo nos processos regenerativos pós-hepatectomias ${ }^{4}$. Considera-se o

1. Professor Titular do Departamento de Cirurgia da Faculdade de Medicina - UFMG; Docente Livre da Faculdade de Medicina de Ribeirão Preto - USP; Docente Livre da Escola Paulista de Medicina - UNIFESP; Doutor em Fisiologia e Farmacologia; Pesquisador IA do CNPq.

2. Médico.

3. Professor Titular de Patologia da Faculdade de Medicina da UFMG.

4. Residente de Cirurgia Geral do Hospital Júlia Kubitschek - FHEMIG. 
fluxo porta como o principal fator que contribui para a resposta regenerativa do fígado. O aumento da perfusão hepática decorre de diferença pressórica entre a veia porta e artéria hepática na parte remanescente ${ }^{1,5}$. Nos casos de obstrução ao sangue porta ou seu desvio por uma derivação portassistêmica, verifica-se a diminuição do tamanho hepático. No caso de hepatectomia parcial, a regeneração do remanescente hepático é muito retardada em presença de baixo fluxo porta. Entretanto, a síntese de DNA e a atividade mitótica continuam preservadas e até aumentadas, o que caracteriza a hiperplasia ${ }^{2}$.

Considera-se que fatores de crescimento e seus respectivos receptores celulares controlam a replicação dos hepatócitos ${ }^{1,5-8}$. O processo resulta de um sistema de sinais intra e extra-hepáticos que ocorrem entre os hepatócitos e outras células parenquimatosas ou não (mecanismos parácrinos). Mullhaupt et $a l^{9}$ evidenciaram mediante modelo envolvendo cultura celular, que a proliferação dos hepatócitos é regulada predominantemente por mecanismos autócrinos, a partir da liberação de fatores de crescimento. Os hepatócitos previamente estimulados seriam capazes de produzir seus próprios fatores de crescimento, caracterizando a regulação autócrina. Esses hepatócitos também respondem a fatores de crescimento produzidos por outras células hepáticas, constituindo a regulação parácrina. Células de outros órgãos promovem a regulação endócrina por meio de receptores de membrana celular dos hepatócitos. Entre eles, destacam-se o fator de crescimento de hepatócitos (HGF), o fator de crescimento epidérmico (EGF) e o fator de crescimento de transformação (TGF), além dos fatores gerais já estabelecidos ${ }^{1,10-13}$.

Ao redor de $45 \%$ dos traumas fechados e $40 \%$ dos traumas abertos atingem o fígado, sendo que, se forem observados pequenos ferimentos superficiais, essas cifras podem atingir até mais de $80 \%{ }^{14}$. Dependendo da extensão da ferida, o sangramento pode colocar o paciente em risco de morte em $25 \%$ a $56 \%$ dos casos. Os ferimentos hepáticos tendem a produzir feridas com rupturas explosivas ou lacerações na superfície hepática, freqüentemente com considerável destruição parenquimatosa. ${ }^{14-17}$.

Tendo em vista os aspectos acima comentados, propusemos, neste trabalho, avaliar a regeneração hepatocitária nos seus aspectos macro e microscópicos em pós-operatório de ressecções parciais do fígado.
O presente trabalho foi realizado de acordo com as recomendações das Declarações de Helsinque e as Normas Internacionais de Proteção aos Animais, e foi aprovado por Comissão de Ética da UFMG $^{18,19}$.

\section{MÉTODO}

Foram estudados 10 ratos machos albinos da raça Wistar, pesando entre 250 e 300 gramas.

Sob anestesia inalatória com éter sulfúrico, foi realizada laparotomia mediana com $3 \mathrm{~cm}$ de extensão. Com o auxílio de um bisturi de lâmina, ressecou-se parte do lobo esquerdo hepático, em uma extensão de aproximadamente $20 \%$ do tamanho do órgão. A hemostasia foi feita com sutura contínua, utilizando-se fio de categute simples 5-0. A parede abdominal foi fechada em dois planos (aponeurose e pele) com fio de polipropileno 3-0. Os ratos recuperaramse espontaneamente da anestesia.

Os animais foram avaliados diariamente, e receberam água e ração para ratos ad libitum.

Após o procedimento cirúrgico, os ratos foram divididos aleatoriamente em dois grupos $(n=5)$, para estudo evolutivo da morfologia hepática macro e microscópica, no período pós-operatório:

- Grupo 1: sétimo dia pós-operatório;

- Grupo 2: vigésimo-primeiro dia pós-operatório.

Os fragmentos hepáticos retirados durante as hepatectomias foram considerados como controle e estudados à microscopia óptica.

Decorrido o tempo de acompanhamento, os animais foram mortos com dose letal de éter. Realizou-se uma segunda laparotomia na qual avaliouse o aspecto macroscópico do fígado. Em seguida, retiraram-se fragmentos da borda hepática que havia sido seccionada, para análise histológica. Após a fixação dos fragmentos em formol a 10\%, eles foram processados para histologia. Secções de $5 \mu \mathrm{m}$ de espessura foram montados em lâmina e corados com hematoxilina e eosina. Avaliaram-se, microscopicamente, as áreas de cicatrização e a morfologia do parênquima hepático. Estudou-se a ploidia dos hepatócitos mediante cálculo de seu volume nuclear. Mediu-se, com auxílio de ocular microcinética, o diâmetro médio do núcleo dos hepatócitos esféricos e calculou-se o volume nuclear pela fórmula: $v=4 / 3 \pi r^{3}$. Em cada fragmento do fígado, mediram-se aleatoriamente 100 núcleos de hepatócitos. 
Compararam-se os resultados das médias dos volumes nucleares pelo teste t Student. As diferenças foram consideradas significativas para valores maiores aos correspondentes a $\mathrm{p}<0,05$.

\section{RESULTADOS}

Os animais evoluíram satisfatoriamente. Não houve morte precoce ou infecção nos pós-operatórios de ambos os grupos estudados. Todos os animais tiveram atividade motora aparentemente normal dentro das gaiolas.
No Grupo 1, após sete dias, os animais apresentaram a cavidade abdominal com poucas aderências. O fígado não evidenciou sinais de congestão. Houve crescimento do órgão até suas dimensões próximas ao normal. Sua borda esquerda estava cicatrizada. $\mathrm{O}$ exame histopatológico revelou fibrose de aspecto jovem, em evolução. Havia abundante tecido de granulação entremeado por discreto infiltrado inflamatório, constituído por mono e polimorfonucleares. O parênquima hepático próximo à área cicatricial desenvolveu poliploidia celular acentuada (Figura 1).

\section{Representação do volume nuclear dos hepatócitos}
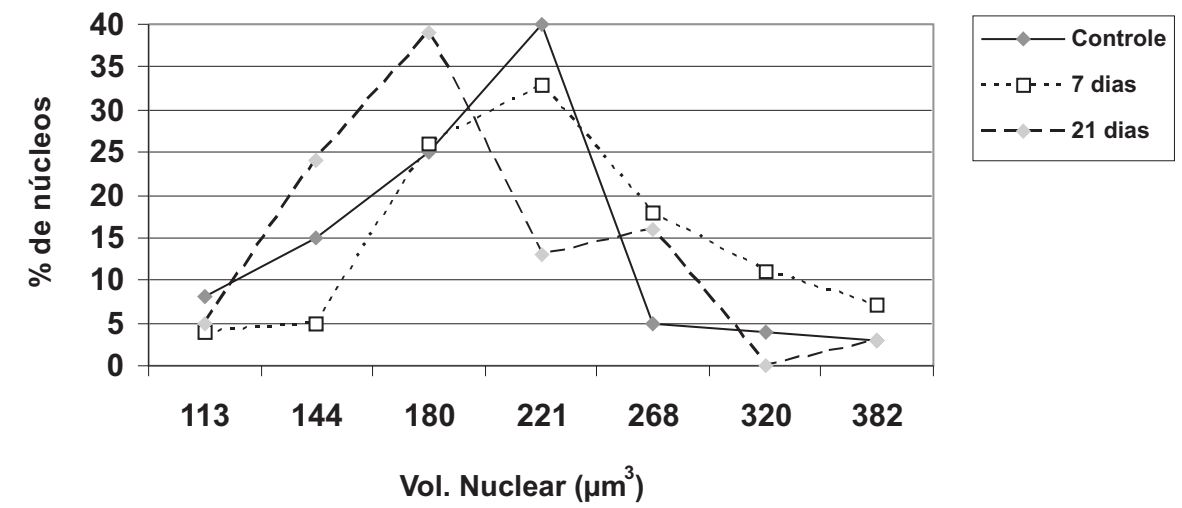

Gráfico 1 - A área dos gráficos mostra um predomínio de núcleos poliplóides na curva correspondente ao Grupo de sete dias em relação aos outros dois grupos ( $p<0,05)$.

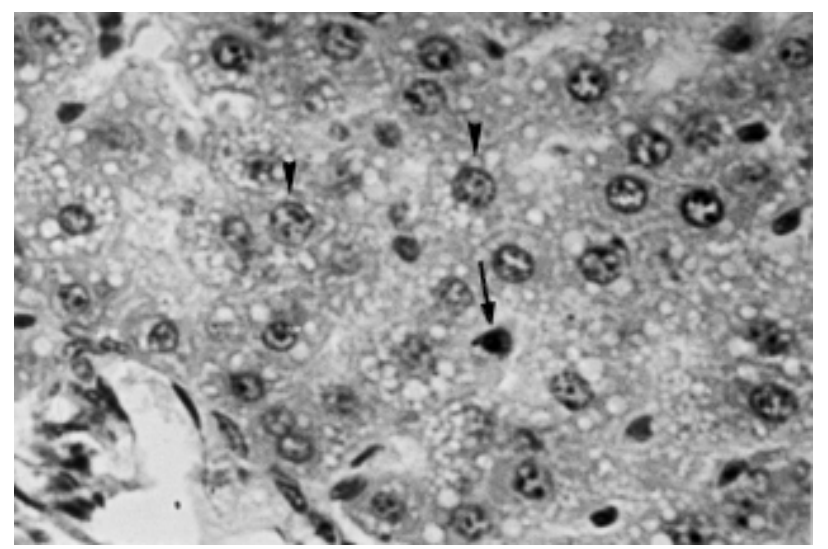

Figura 1 - Quadro histológico do parênquima hepático de ratos, sete dias após hepatectomia parcial. Observar presença de núcleos volumosos, poliplóides (cabeças de setas) e figuras de mitoses (seta). (hematoxilina e eosina, $200 \mathrm{X}$ )
O Grupo 2, após 21 dias, a cavidade abdominal ainda apresentou aderências frouxas e difusas. Microscopicamente, observou-se fibrose extensa com tecido cicatricial mais denso, ordenado, sem sinais inflamatórios. A poliploidia dos hepatócitos tornou-se discreta ou ausente.

O Gráfico 1 registra predomínio de núcleos poliplóides principalmente no Grupo 1 em relação ao controle $(p<0,05)$. Não houve diferença entre o Grupo 2 e o controle.

\section{DISCUSSÃO}

A literatura relata aumento da poliploidia hepatocitária com a idade e sugere que as mudanças funcionais em fígados de ratos, com o decorrer do 
tempo, não envolvem alterações somáticas importantes ${ }^{4}$. Tal fato foi de importância na seleção dos animais estudados, já que foram selecionados ratos de uma mesma linhagem e idade, e dentro de uma mesma faixa de peso.

Nos últimos anos, pesquisas buscam esclarecer os fenômenos regenerativos hepáticos ${ }^{6,10,20,21}$. A hiperplasia hepatocitária é resultado de dois processos: diminuição nas células diplóides binucleadas com conseqüente aumento das células mononucleadas tetraplóides e aumento nas células diplóides em decorrência de divisão celular. Este último processo parece ser responsável pela maioria das figuras mitóticas celulares.

Segundo Soames ${ }^{22}$, estimulação hepatocitária em decorrência de proliferação peroxissomal, a distribuição lobular dos hepatócitos em mitose predomina nas regiões periporta, seguida pela intermediária e depois centrolobular. Todavia, esse relativo padrão segmentar de mitoses é distinto do aspecto observado após hepatectomias parciais, nas quais há preponderância inicial de mitoses nas regiões periporta, e uma seqüência de mitoses que envolvem as células centrolobulares ${ }^{21}$. No presente trabalho, encontraram as figuras mitóticas nessas duas regiões. De acordo com outros trabalhos, a distribuição da hiperplasia é influenciada pela irrigação sangüínea e pode ser revertida se for alterado o sentido desse fluxo ${ }^{5,8,21,23}$.

A utilização do fio de categute, rapidamente absorvível, nas suturas hepáticas visou a reduzir a influência que o material do fio pudesse ter sobre o fígado. À avaliação histológica não se encontrou reação decorrente da sutura.
A ausência de infecções no presente trabalho tem sido explicada pela literatura ${ }^{15,24,25}$. Ao contrário de lesões proporcionalmente menores do baço e que se acompanham de quadros sépticos ${ }^{26}$, as operações sobre o fígado são bem toleradas e raramente comprometem o sistema imunitário.

A análise do Gráfico I mostra a prevalência de núcleos poliplóides apenas no grupo estudado após os sete dias da hepatectomia parcial. Esse dado evidencia proliferação aumentada dos hepatócitos nesse período. Ainda que as células parenquimatosas sejam responsáveis por cerca de $60 \%$ da população celular, elas são responsáveis por mais de $95 \%$ do volume hepático ${ }^{2,10}$. Em conseqüência, houve crescimento do fígado até seu tamanho original já nesse período, o que foi comprovado na avaliação macroscópica.

Após três semanas de evolução pós-operatória não se detectaram alterações histológicas relevantes, sugerindo que o processo de regeneração hepática havia terminado.

Concluindo, após a remoção cirúrgica de cerca de $20 \%$ do parênquima hepático de ratos, observou-se inicialmente, crescimento celular por meio de poliploidia hepatocitária. Após três semanas, o órgão retornou a suas condições anatômicas e histológicas originais.

\section{AGRADECIMENTOS}

Os autores agradecem ao CNPq e FAPEMIG pelos auxílios financeiros que permitiram a realização deste trabalho.

\begin{abstract}
Background: To assess the progression of liver regeneration after partial hepatic resection. Methods: Ten Wistar adult rats, of both sexes were studied. After anesthesia with ether, the animals were submitted to a left lobe parcial hepatectomy. Rats were randomly divided into two groups $(n=5)$ according to the day macro and microscopic studies were carried out, $7^{\text {th }}$ (Group 1) or $21^{\text {st }}$ postoperative days. Results: All rats survived throughout the experimental protocol. The main finding on the seventh day was intraabdominal adhesions. Microscopical examination showed hepatocyte proliferation (polyploid nuclei, mitotic activity) and pattern of acute inflammation. On the twenty-first day, liver aspect was normal. No inflammatory response was observed, and only a few poliploid nuclei were found.Conclusion: Recovery of the liver occurs after partial hepatectomy by means of hepatocyte poliploidy.
\end{abstract}

Key Words: Liver; Liver regeneration; Polyploidy. 


\section{REFERÊNCIAS}

1. Fausto N, Mead JE-Regulation of liver growth: protooncogenes and transforming growth factors. Lab Invest, 1989, 60(1):4-13.

2. Karran S, Eagles C, Bucher LR, et al - "Regeneration". In Wright A (ed) - Liver ad biliary disease. Philadelphia. Saunders, 1979, pp 197-227.

3. Fletcher K, Orton TC, Chipman JK, et al - The response of hepatocytes isolated from phenobarbitone treated mice to mitogenic growth factors. Arch Toxicol, 1997, 71(7):422-428.

4. Becker FF, Lane BP-Regeneration of the mammalian liver. I. Auto-phagocytosis during dedifferentiation of the liver cell in preparation for cell division. Am J Pathol, 1965, 47(5):783-801

5. Sigel B, Baldia LB, Brightman SA, et al - Effect of blood flow reversal in liver autotransplants upon the site of hepatocyte regeneration. J Clin Invest, 1968, 47(6):12311237.

6. Hall PA, Levison DA - Review: assessment of cell proliferation in histological material. J Clin Pathol, 1990, 43(3):184-192.

7. Sakaguchi K, Takeuchi E, Suzuki M, et al. - DNA polymerases and Ki-67 nuclear antigen are induced in correlation with the resected mass of rat liver up to 90\%. Langenbecks Arch Surg, 2000, 385(2):135-142.

8. Sarraf CE, Horgan M, Edwards RJ, et al - Reversal of phenobarbital-induced hyperplasia and hypertrophy in the livers of Ipr mice. Int J Exp Pathol, 1997, 78(1):4956.

9. Mullhaupt B, Feren A, Fodor E, et al. - Liver expression of epidermal growth factor RNA. Rapid increases in immediate-early phase of liver regeneration. J Biol Chem, 1994, 269(31):1967-1970.

10. Callea F, Brisigotti M, Fabbretti G, et al - Cirrhosis of the liver. A regenerative process. Dig Dis Sci, 1991, 36(9):1287-1293.

11. Eguchi S, Okudaira S, Azuma T, et al. - Changes in liver regenerative factors in a case of living-related liver transplantation. Clin Transplant, 1999, 13(6):536544.

12. Feliciano DV, Pachter HL - Hepatic trauma reviseted. Curr Probl Surg, 1989, 26(7):453-524.

13. Ohmura T, Ledda-Columbano GM, Piga R, et al. Hepatocyte proliferation induced by a single dose of a peroxisome proliferator. Am J Pathol, 1996, 148(3):815824.
14. Skullman S, Wirén M, Garlick PJ, et al - Protein synthesis in regenerating rat liver during malnutrition. J Hepatol, 1994, 21(2):174-181.

15. Nadal SR, Duarte E, Arouca U, et al. - Trauma hepático isolado. Rev Col Bras Cir, 1991, 18(5):188-192.

16. Araujo ID, Silva AA, Okawa RY, et al - Alterações histológicas em fígado de ratos ictéricos após uso de sais biliares exógenos por via oral. Rev Bras Cir, 1997, 87(2):79-81.

17. Petroianu A, Silva RTF, Barbosa AJ, et al. - Alterações morfológicas do fígado após secção hepática parcial e omentoplastia. Rev Col Bras Cir, 1998, 25(1):15-27.

18. Way LW. "Fígado". In Way LW (ed) - Cirurgia. 9a edição. Rio de Janeiro. Guanabara Koogan, 1993, pp. 362369.

19. Cooper JE - Ethics and laboratory animals. Vet Rec, 1985, 116(22):594-595.

20. Petroianu A. "Pesquisa experimental". In Petroianu A (ed) - Ética, Moral e Deontologia Médicas. $1^{\mathrm{a}}$ edição. Rio de Janeiro. Guanabara Koogan, 2000, pp. 185-190.

21. Silvestrini R, Costa A, Regalia E - Cell kinetics in the study of hepatocellular carcinoma. Ital J Gastroenterol, 1992, 24(1): 43-45.

22. Soames AR, Foster JR - Juxtaposition of peroxisomes and chromosomes mitotic hepatocytes following methyl clofenapate administration to rats. Int J Exp Pathol, 1994, 75(6):405-414.

23. Ryoo JW, Buschmann RJ - A morphometric analysis of the hypertrophy of experimental liver cirrhosis. Virchows Arch A Pathol Anat Histopathol, 1983, 400(2):173-186.

24. Popper H - Regulatoroy modulation in hepatology. Hepatology, 1987, 7(3): 586-590.

25. Petroianu A, Trapiello Neto V, Esquerdo CRM, et al. Efeito da secção hepática parcial e omentoplastia na regeneração hepática de cão. Rev Col Bras Cir, 1999, 26(3):181-184.

26. Rutherford EJ, Morris JA, Van Aalst J, et al. - The white blood cell response to splenectomy and bacteraemia. Injury, 1994, 25(5):289-292.

Endereço para correspondência:

Prof. Andy Petroianu

Av. Afonso Pena, $n^{\circ} 1626$ / apto. 1901

CEP: 30130-005 - Belo Horizonte, MG.

Fone/Fax: (31) 3274-7744

E-mail: petroian@medicina.ufmg.br 